REMLATE DE MALIES

Campinas-SP, v.41, n.1, pp. 76-97, jan./jun. 2021

\title{
RECONFIGURAÇõES ético-reparadoras DO LITERÁRIO HOJE
}

\section{ETHICAL-REPARATIVE RECONFIGURATIONS OF THE LITERARY TODAY}

\author{
André Cechinel ${ }^{1}$
}

Resumo: O presente ensaio propõe-se a debater indícios de uma função ético-reparadora para a literatura e os estudos literários hoje. Para tanto, divide-se em dois momentos fundamentais, dois canais argumentativos que, sem um intuito totalizante, apontam as linhas gerais de um cenário em mutação. De um lado, a literatura do século XX é apresentada a partir da imagem de uma suposta negatividade ou intransitividade radical, capaz de "desobrar a obra" em sua "estética da supressão". De outro lado, a partir de um debate introdutório em torno de alguns dos lugares de transitividade vislumbrados para a literatura neste início de século XXI, o literário é concebido agora como campo ético-reparador, responsável, entre outros, por "dar visibilidade", "lembrar", "reparar danos", "confortar" etc. Resulta dessa transição a noção de um crescente desconforto em relação aos artefatos sociais que, inclusive no campo artístico, não se reconciliam com um utilitarismo que nada pode deixar intacto, nem mesmo a literatura.

Palavras-chave: literatura, intransitividade, virada ética.

Abstract: This essay aims to debate the evidence of an ethical-reparative function for literature and literary studies today. Therefore, it is divided into two fundamental moments, two argumentative channels that, without a totalizing intention, point out the general perspective of a changing scenario. On the one hand, the literature of the $2 \mathrm{O}^{\text {th }}$ century is presented from the image of a supposed negativity or radical intransitivity, capable of "undoing the work" in its "aesthetics of suppression". On the other hand, from an introductory debate around some of the places of transitivity envisioned for literature at the beginning of the $21^{\text {st }}$ century, the literary is now conceived as an ethical-reparative field, responsible, among others, for "giving visibility", "remembering", "repairing damage",

${ }^{1}$ Departamento de Letras, Universidade do Extremo Sul Catarinense: <andrecechinel@ gmail.com>. 
"comforting," etc. This transition results in a notion of growing discomfort in relation to social artifacts that, even in the artistic field, cannot be reconciled with a utilitarianism that cannot preserve anything intact, not even literature.

Keywords: Literature; Intransitivity; Ethical Turn.

\section{INTRODUÇÃO}

Dispositivo crítico repetidas vezes acionado no último século - e mesmo antes -, o anúncio do fim ou da crise da literatura constitui, como se sabe, um dos motores discursivos mais caros tanto à crítica literária quanto à atividade dos próprios escritores. Tanto isso é verdade, que a constatação da parcialidade desse anúncio, encarado como desmedido e apocalíptico, revela-se, por sua vez, não menos constante e presente do que o fenômeno a ser refutado. Em outras palavras, se, por um lado, o fim da literatura ou da leitura literária é problematizado, vislumbrado ou profetizado por nomes como George Steiner (2007), Alfonso Berardinelli (2007), Tzvetan Todorov (2009), Antoine Compagnon (2009), entre outros, por outro lado, não menos numerosos são aqueles que se lançam a declarar que o diagnóstico do fim ou da crise não só é há muito familiar, como também serve para alimentar ou reavivar os movimentos da literatura que lhe asseguram uma sobrevida aparentemente perene. No Brasil, como exemplo do debate teórico que compreende o fim e a crise como estratégias criativas e de pensamento para o espaço literário, podemos citar os estudos recentes de Marcos Siscar (2010; 2016).

Seja como for, se pensarmos em termos de um contínuo, em que o improvável declínio ou desaparecimento da literatura ocuparia um dos extremos, é certo que o frequente anúncio da sua morte situa-se num ponto menos periférico e se refere, acima de tudo, à percepção de que algo mudou, de que determinada forma ou registro, antes predominante, já não traduz com exatidão as operações fundamentais de um objeto que permanece, contudo, sem essência, informado retrospectivamente por seu percurso posterior e incerto. Em vez de "fim", "morte", "declínio" ou "desaparecimento", caberia apontar, então, "índices de mutações" (PERRONE-MOISÉS, 2016), sinais da travessia de um regime literário para outro, da perda de contemporaneidade de determinada definição sua, ou da passagem de uma valorização ou função social para uma nova fase, papel ou situação que atualiza significativamente o seu quadro conceitual. O livro de Leyla Perrone-Moisés intitulado Mutações da literatura no século $X X I$, datado de 2016, ocupa-se justamente disso, de afastar a "morte" ou 
"fim" do literário de sua esfera apocalíptico-decadentista, aquela do ponto extremo do contínuo, mas, ao mesmo tempo, de sinalizar um momento de "mutações", de transformações - tecnológicas, econômicas, culturais, institucionais etc. - que alteram a sua "natureza".

O presente ensaio propõe-se a indicar um desses possíveis “índices de mutação", que poderia ser formulado, em linhas gerais, nos termos de um gradativo descrédito ou desuso da ideia de "intransitividade", "inutilidade" ou "negatividade" da literatura - traços seus não raro compreendidos como radicais e políticos ao longo do século XX -, em nome de um crescente pragmatismo "ético-reparador" segundo o qual os artefatos literários teriam de atuar diretamente sobre o real, aproximando-nos dos "outros" seres (humanos, animais, natureza etc.), ensinando-nos a viver melhor e a ter autoconfiança, apresentando-nos o passado silenciado pelos vencedores da história oficial, enfim, "fazendo o bem". No livro Réparer le monde, Alexandre Gefen (2017, p. 17) resume assim a questão: no início do século XXI, a literatura já "não é um fim em si mesma, mas sim um dispositivo social ou simbólico poderoso que opera sobre as consciências e os corações". O que Gefen chama de virada "terapêutica”, portanto, diz respeito a um desejo de transitividade, à tarefa de retirar a literatura do domínio reservado à suposta aristocracia "dos eleitos" - expressão reiterada em vários momentos do seu livro - para, a seguir, restituí-la ao uso dos indivíduos comuns: "a literatura [...] torna-se hoje, então, um remédio para a alma” (p. 16).

A fim de sustentar o argumento em torno dessa transição da literatura como intransitividade para um impulso "ético" e "reparador" de corações, almas, biografias e histórias, este ensaio se divide em dois momentos: primeiro, a partir da reconstituição de cenas decisivas da arquitetura da destruição ou do esgotamento ficcional, apresentadas por Dominique Rabaté (2004) e características da literatura do século XX, busca-se expor uma imagem do literário como escrita subtrativa, corrosiva e negativa, capaz de apagar, suprimir, fazer desaparecer e, fundamentalmente, de "desobrar" ou violentar a obra e suas categorias tradicionais; a seguir, atravessando diferentes fenômenos cada vez mais frequentes da "virada terapêutica" - como o império das autoficções, autobiografias, biografias e outros modos de escrita e revelação de si; a significativa presença e circulação de volumes com propósitos declaradamente políticos e de intervenção, que se propõem a "dar visibilidade", "lembrar", "fazer justiça”, 
"reparar danos", "confortar" etc.; o crescimento dos "estudos da memória”" e a "virada ética" nos estudos literários; e, por fim, a lógica de meios e fins que instrumentaliza e "terapeutiza" o ensino de literatura na nova Base Nacional Comum Curricular (CECHINEL, 2019) -, pretende-se assinalar, como dito, o índice ou indício de mutação ético-reparadora do literário hoje. Como conclusão, aqui antecipada, pode-se sugerir um alinhamento evidente entre a literatura - ou os estudos literários - e a necessidade de justificar transitiva, pragmática e utilitariamente o lugar ético-político e institucional dos seus objetos; da mesma forma, a chamada sociedade narcísica e autofágica (JAPPE, 2019) - sociedade do rendimento, da depressão e do "cansaço de si" (EHRENBERG, 1998) -, incapaz de se opor diretamente à violência do espetáculo contemporâneo, atua no sentido de converter os objetos artísticos e demais resíduos de intransitividade em terapia positivadora como elemento reintegrador.

\section{“DESOBRANDO” A OBRA}

Em seu livro Vers une littérature de l'épuisement, D. Rabaté (2004) defende a tese de que a literatura do século XX é marcada pela aparição recorrente de obras - como as de Kafka, Beckett, Blanchot, Camus (poderíamos acrescentar, no Brasil, por exemplo, Clarice Lispector) - que vislumbram uma poética do esgotamento, da desaparição, da rarefação e, em última instância, da própria morte. São narrativas que, diante das catástrofes do século XX e da aparente falência ou insuficiência explicativa dos discursos míticos, religiosos, filosóficos e científicos da modernidade, voltam-se para a encenação de um profundo abandono metafísico, linguístico e existencial, convertido agora em procedimento estético. Personagens órfãos, sem nome, ou cujo nome é apenas uma sigla, sem biografia, sem história, sem passado; enredos sem começo, sem desenvolvimento linear, sem desfecho evidente; espaços sem identidade, sem paisagem, indiferenciados, sem memória, sem localização; um tempo difuso, eternamente presente, sem projeções ou recuos descritivos e esclarecedores; uma linguagem tateante, cujos referentes instáveis limitam-se a remeter a novos significantes, num deslizamento angustiante e sem promessa de redenção, cancelando autorias, propriedades, origens e destinos. Tudo isso integra o cenário da literatura no século $\mathrm{XX}$, não exclusivamente, é claro, mas pelo menos de modo constante

${ }^{2}$ Cf. Durão e Tinti (2019; 2020). 
ou mesmo dominante, conforme resumido por Rabaté (2004, pp. 11 e 18, respectivamente, grifos meus):

\begin{abstract}
O esgotamento é o programa estético de uma certa época da literatura à qual talvez não pertençamos mais. [...] A imaginação romanesca do leitor parece dever se mobilizar de uma maneira diferente, menos no sentido de visualizar os lugares ou os personagens, segundo seus costumes ou traços físicos, e mais para descobrir o traço singular desse discurso desencarnado. O esforço da ficção reside nesse discurso, que, por sua vez, exige muito de nós.
\end{abstract}

Esse "discurso desencarnado" é, a rigor, tanto expressão do esgotamento do esquema estável de gêneros e formas ditado pelos regimes representativos que regularam a literatura até então, quanto um programa estético-literário corrosivo, marginal, imprevisto, "desidentificador", que passa não só a demandar que cada obra construa internamente e a partir de si mesma as regras do seu jogo, da sua linguagem, como também a inaugurar um "eu" em crise, incapaz de identificar-se consigo mesmo, com o outro, com o mundo, com a linguagem, com o espaço, com a história. Nesse processo de desfamiliarização, o sujeito não se reconhece, nem pode se reconhecer, como coincidindo com quem aparenta ser, com quem julga ser, com as palavras que utiliza, e o seu universo interpretativo, bem como os sentidos que busca construir, começam a colapsar. Ler a si mesmo é reconhecer-se "qualquer", é descobrir a precariedade sobre a qual a linguagem e o "eu" se assentam e se estruturam; é, em suma, assumir a contingência existencial, a ambivalência dos signos e da vida, e, com isso, apagar-se gradativamente e perder-se do mundo. Que esse "perder--se do mundo", "perder o mundo", acabe por se converter em diferentes possibilidades estéticas, isso a literatura do século XX, em suas várias tradições, deixou muito claro.

Ora, não é a dissolução do sujeito autocentrado e uma escrita que se arrasta como questão e força desconstrutiva o que vemos constantemente nessa literatura da supressão? Exemplos, afinal de contas, não faltam. Em O castelo, de 1922: "Eles andavam, mas K. não sabia para onde, não era capaz de reconhecer nada [...]. Por causa do esforço que o simples andar lhe causava, acontecia não estar em condições de controlar seus pensamentos" (KAFKA, 2000, p. 49); em A montanha mágica, de 1924: "Aqui não fazem muita cerimônia com o tempo da gente. Você não tem ideia. Três semanas são para eles como um dia, vai ver. Tudo isso se aprende. [...] Aqui todas as concepções se transformam” (MANN, 2006, p. 20); em O inominável, de 1953: "Onde agora? Quando agora? Quem agora? Sem me perguntar isso. 
Dizer eu. Sem o pensar. Chamar isso de perguntas, hipóteses. Ir adiante, chamar isso de ir, chamar isso de adiante" (BECKETT, 2009, p. 29); em Pedro Páramo, de 1955: "Vim a Comala porque me disseram que aqui vivia meu pai, um tal de Pedro Páramo. Minha mãe me disse. E eu prometi que viria vê-lo assim que ela morresse" (RULFO, 2008, p. 25); em Água viva, de 1973: "E eu inteira rolo e à medida que rolo no chão vou me acrescentando em folhas, eu, obra anônima de uma realidade anônima só justificável enquanto dura a minha vida" (LISPECTOR, 1998, p. 22). As perguntas, dúvidas e angústias golpeiam os personagens e as formas narrativas, dificultam o acesso aos sentidos da obra, desconectam o caminho das palavras às identidades e, assim, demandam do leitor uma postura crítica, criativa e, de certo modo, também ela "autora" do objeto em questão.

A linguagem "desencarnada" é uma linguagem que, ao suspender o trajeto tranquilo rumo às identidades e identificações permanentes e contestar os efeitos das vozes sobre a presença "em si" e familiar dos fatos, emancipa-se e migra em direção a si mesma, ou melhor, demonstra que a literatura só pode atuar no mundo - transgredir, denunciar, revelar, inspirar etc. - por meio do contato direto, inventivo e angustiante com uma linguagem que resiste, desampara, interrompe e - segundo as formulações mais recorrentes de determinada crítica, por vezes repetidas como um mantra - desaparece e morre diante de nossos olhos.

A palavra me dá o ser, mas ele me chegará privado de ser. [...] Portanto, quando falo, a morte fala em mim. Minha palavra é a advertência de que a morte está, nesse exato momento, solta no mundo, que entre mim, que falo, e a pessoa que interpelo, a morte surgiu subitamente (BLANCHOT, 1997, pp. 312-313).

A palavra literária corresponde à consciência de uma presença-ausente, à tentativa de preencher uma lacuna que, contudo, na impossibilidade de converter-se em coisa, arrasta consigo ou denuncia o caráter fantasmático dos signos. Experiência órfica, a literatura, enfim, evoca o real no exato instante em que nos afasta dele.

Celebrar o vínculo entre escrita e desaparecimento, entre o trabalho produtivo de fabricar a linguagem e o exercício "negativo" de conviver com a perda, significa, é claro, um desafio ao pensamento, agora liberado de qualquer origem rígida ou ponto de convergência final e reparador autor, contexto, recepção - para a aventura imprevisível de uma "conversa infinita". A literatura realiza a tarefa de neutralização e recusa da suposta função explicativa, por exemplo, do autor, figura conduzida à morte tão logo admitido o "aqui" e "agora" da escritura para 
[...] o scriptor moderno [...], a sua mão, desligada de toda a voz, levada por um puro gesto de inscrição (e não de expressão), traça um campo sem origem - ou que, pelo menos, não tem outra origem para lá da própria linguagem, isto é, exatamente aquilo que repõe incessantemente em causa toda a origem (BARTHES, 2004, p. 61).

Seé bem verdade que essa contínua celebração da multiplicidadecomoalgo "bom em si mesmo" também contribui significativamente para o cenário de desmantelamento da noção de artefato ou obra nos estudos literários - fato que, por sua vez, tem participação direta nos desdobramentos que conduzem a uma ideia terapêutica de literatura e a uma noção deslizante de texto, que assume qualquer atrito ou obstrução como gesto impositivo contra o livre fluxo, "consumo" e "prazer"3 da leitura -, a "morte do Autor" de fato rompe com a tradição, consolidada em diversos manuais da literatura, de apaziguar a obra literária a partir de elementos como datas de nascimento e morte ou uma gramática estética apriorística, colada de modo informativo aos objetos.

O "prazer" ou "gozo" da leitura ainda é, nesse momento, não a positividade moral de uma escrita reparadora que faz justiça ao mundo, que nos aproxima dos outros, que nos torna melhores do que aqueles apartados da sacralidade do literário, ou que nos permite um autoconhecimento revelador, mas sim um prazer "restritivo" e vinculado, sobretudo, às operações de uma linguagem que só pode "desvelar" o mundo ao voltar-se para si mesma e para suas construções particulares. O dever de "fazer o negativo”, programa estético fundamental do século XX anunciado por Kafka, encontra ressonância em diversos outros artistas e teóricos da negação: "a violência com que Kafka reclama interpretação encurta a distância estética. Ele exige do observador pretensamente desinteressado um esforço desesperado, agredindo-o e sugerindo que sua correta interpretação [...] é uma questão de vida ou morte" (ADORNO, 1998, p. 256). Tal como o sono 4 e outras dimensões criativas e "improdutivas" da vida humana, que não podem ser capitalizadas como mercadorias e colocadas no fluxo do consumo, a literatura e a integralidade do artefato artístico impõem-se como desafio à atenção e necessidade de entrega total do leitor, sem, contudo, promessa de superação das dificuldades ou

3 Para uma crítica da multiplicidade nos estudos literários, sugiro a leitura do livro intitulado Do texto à obra e outros ensaios (2019), de Fabio A. Durão.

${ }^{4}$ Cf. Crary (2014). 
reconciliação posterior. A negatividade do literário revela-se como enigma e exigência permanente de releitura:

O que está contido na bola de vidro de Kafka é mais coerente e portanto mais cruel ainda do que o sistema lá fora [...]. A interioridade que, sem resistência, gira ao redor de si mesma é negada, e aquilo que poderia pôr termo ao movimento falsamente infinito transforma-se em enigma (ADORNO, 1998, p. 259).

A poética do esgotamento e da negação, longe de atuar sob o princípio do acúmulo indistinto, da contínua autopromoção nos campos de visibilidade, por vezes flerta perigosamente com o extremo de sua aniquilação: artista da fome, incapaz de encontrar o alimento que o faria empanturrar-se feito todo mundo, Kafka solicita que seu amigo Max Brod queime os seus escritos após a sua morte. Juan Rulfo, depois do sucesso de Pedro Páramo, adia indefinidamentea publicação do seu segundo romance, sempre sob pretextos pouco convincentes: a morte do tio contador de histórias, o excesso de livros em circulação. A queima literária arquitetada por Kafka não lhe era estranha: após não obter resposta alguma das editoras, decide eliminar o seu romance intitulado $O$ filho do desalento, dando sinais da mesma recusa que depois o singularizaria. Robert Walser sempre se considerou um sujeito menor e também se entregou a um longo silêncio, em meio a caminhadas sem fim e sem destino, incorporando biograficamente a trajetória negativa de seus personagens:

Hoje, vamos ter de nos contentar com absolutamente nada, não é mesmo? Absolutamente nada é o que há de mais rápido para preparar e, de todo modo, não causa indigestão. Excepcionalmente [...], jantaram absolutamente nada, e o marido [...] tampouco ficou bravo, de jeito nenhum (WALSER, 2014, p. 72).

\section{Vladimir Maiakovski, Horacio Quiroga, Virginia Woolf, Ernest} Hemingway, Stefan Zweig, José María Arguedas, Primo Levi, Sylvia Plath, Paul Celan, David Foster Wallace, Ana Cristina César, Torquato Neto escritores suicidas cujas vidas - nem sempre exemplares de uma ética reparatória, vale lembrar - aproximam-se antes do dispêndio, da perda, do improdutivo, do sacrifício, das paixões do que do caráter preservador da utilidade:

Toda vez que o sentido de um debate depende do valor fundamental da palavra útil, ou seja, toda vez que uma questão essencial referente à vida das sociedades humanas é abordada, quaisquer que sejam as pessoas que intervêm e quaisquer que sejam as opiniões representadas, é possível afirmar que o debate é necessariamente falseado e que a questão fundamental é eludida (BATAILLE, 2013, p. 36). 
Seja como for, a literatura como negatividade ou dispêndio parece vincular-se a uma época "à qual talvez não pertençamos mais", ou, nos termos do nosso contínuo, uma época com a qual os escritores e seus projetos literários já não coincidem de maneira dominante. Se "fabricar o negativo" correspondia à tarefa fundamental do século XX, hoje a herança da estética da supressão, do gesto de "desobrar" a obra, aponta cada vez mais para uma direção contrária:

[...] o clima [...], volta-se declaradamente para a positividade do fato literário, que se situa nas antípodas da paixão pelo impossível que havia animado a literatura passada. Positividade programática [...], num clima de concorrência cultural em que o lugar da literatura como instituição sacralizada é comprometido (RABATÉ, 2018, p. 235).

A obra sem "obra”, ou seja, a textualização dos artefatos artísticos, agora destituídos de sua esfera opositiva e tensionadora, antecipa o cenário de uma recepção que, em vez de desafiada ou desconstruída, anima o seu pedido de transitividade aos objetos: não há tempo a perder, é preciso remediar o mundo. "Definir a obra em relação ao mundo, não à literatura, inscrevê-la na lógica de um trabalho de si e do outro, exigir que ela forneça formas substanciais de saberes históricos ou políticos [...] - são opções literárias bastante evidentes." (GEFEN, 2017, p. 24) Sem propósito totalizante - e admitindo que os quadros aqui listados estão longe de constituir uma imagem total ou exclusiva da literatura hoje -, a próxima seção volta-se para a análise de algumas cenas ou instâncias da "virada terapêutica” em questão.

\section{A OBRA “DESOBRADA"}

No texto intitulado "Discutindo a máquina acadêmica", Fabio Durão e Tauan Tinti expõem uma tendência conceitual, no âmbito das linhas de pesquisa que integram a Pós-Graduação brasileira na área de literatura - mas não exclusiva desta, vale ponderar -, sintomática do fenômeno aqui observado, isto é, do crescente intuito de valer-se das obras literárias num sentido ético-reparador: num recorte de 105 Programas, após as ocorrências mais evidentes de termos como "literatura" (88 Programas) e "cultura" (55 Programas), "memória" aparece como o quarto termo mais frequente das linhas de pesquisa (28 Programas), com apenas 3 ocorrências a menos que o termo precedente, "história", cujo trânsito 
com a literatura é estruturante da área. A memória ultrapassa, segundo o cálculo dos autores,

[...] o vínculo tradicionalmente estabelecido entre literatura e sociedade (23 ocorrências) [...], a soma de linhas voltadas à modernidade (11 ocorrências) e à contemporaneidade (13 ocorrências) [...], e mesmo a área de literatura comparada (16 ocorrências) como um todo (DURÃO; TINTI, 2019a, p. 98).

A aparição significativa e crescente do conceito nas linhas ligadas à literatura aponta a sintonia entre as direções teóricas da área e certo "efeito de moda", que tende a ocorrer, como no caso das mercadorias, no sentido centro-periferia.

Os estudos da memória, em suas formulações mais recorrentes, propõem-se a investigar "o sujeito e corpo como o memorável crítico nas escritas biográficas e autobiográficas" (PPGLit-UFSC), "as articulações entre experiência vivida, ficção e organização social" (Pós-Lit-UFMG), entre outros. No contato efetivo com os artefatos literários, dividem-se, grosso modo, em duas tendências gerais: de um lado, associam-se aos trauma studies e suas categorias correlatas - testemunho, representação, violência, ruínas -, que intentam examinar diferentes narrativas e documentos vinculados às catástrofes históricas, geralmente aquelas do século XX (Shoah e ditadura militar são os objetos mais frequentes), e às aporias linguísticas e testemunhais que os constituem - as referências a Giorgio Agamben são aqui frequentes, ou mesmo incontornáveis; de outro lado, aparecem atrelados à escrita de si, às biografias, autobiografias, autoficções e às operações de um trabalho criativo que se dá nas "fronteiras entre o real e o ficcional, colocando no centro das discussões novamente a possibilidade do retorno do autor" (AZEVEDO, 2008, p. 31). O autor ressurge, agora, não como instância reguladora dos sentidos do texto ou da obra, mas como problema em torno dos limites entre o real e o ficcional, o que contribui para a reflexão sobre o que significa "contar de si", "escrever a si", "revelar sobre si". (Não por acaso, como veremos, as ferramentas de mídias sociais - twitter, facebook, instagram, whatsapp, blogs, fóruns on-line e afins - aparecem como suportes constantes da nova literatura e alvos da investigação crítica, uma vez que convidam o "eu" a se projetar como um híbrido de realidade e invenção). De todo modo, o que vale a pena observar, em ambas as tendências, é o efeito ético-reparador que paira sobre diversas das suas formulações: 
Como o sujeito responde à perda radical? Como funciona o processo de luto e melancolia, economicamente? Quais são as implicações da ideia de que o sujeito, com a perda, se torna um arquivo da perda, um local onde a memória da perda e do trauma é mantida em uma espécie de cripta? Como seria esse arquivo? (BOULTER, 2011, p. 3).

\begin{abstract}
A autoficção é um projeto de autoexploração e autoexperimentação por parte do autor. Isso porque várias obras de autoficção foram escritas após algum tipo de experiência traumática - real ou imaginada -, e, dessa forma, o processo de escrever em resposta ao trauma pode ser visto como uma maneira de situar o eu em um novo contexto [...] (DIX, 2018, p. 4).

A literatura pertenceria a uma psicoterapia mais ou menos voluntária, tanto para o autor quanto para o leitor, que pode reviver e repetir internamente as emoções do texto. Doença na época romântica, a literatura tornou-se um tratamento, e o valor literário é medido quanto à sua eficácia terapêutica, não apenas para quem cura seus traumas verbalizando-os, mas também para o leitor, que encontra no livro um apaziguamento (GEFEN, 2017, p. 98).
\end{abstract}

Um romance que cristaliza muitas dessas tendências - melancolia, trauma privado, luto e escrita reparatória - é o premiado O filho eterno, de Cristóvão Tezza (2007). Desde as epígrafes iniciais, o volume anuncia o cruzamento e cancelamento das fronteiras entre fato e construção criativa - "Queremos dizer a verdade e, no entanto, não dizemos a verdade. Descrevemos algo buscando fidelidade à verdade e, no entanto, o descrito é outra coisa que não a verdade (Thomas Bernhard)" -, bem como o impulso particular, íntimo, confessional ou terapêutico que produz um efeito de acerto de contas com a vida, de reconciliação consigo mesmo e com o mundo - "Um filho é como um espelho no qual o pai se vê, e, para o filho, o pai é por sua vez um espelho no qual ele se vê no futuro (Søren Kierkegaard)" -, ambos traços característicos da chamada autoficção (TEZZA, 2007, p. 5). O romance, como se sabe, narra a difícil jornada de um pai professor/escritor rumo à aceitação do filho com Síndrome de Down, chamado Felipe, e sua maneira particular de ver o mundo. Embora narrado em terceira pessoa e escrito em uma linguagem seca, que objetifica, por vezes ao extremo da frieza, os episódios e sujeitos de que se ocupa, o livro de Tezza volta-se para muitas das experiências do relacionamento entre o próprio autor e seu filho, também chamado Felipe e também com Síndrome de Down.

Se essa biografia ficcionalizada apresenta-se como vontade de declarar a verdade e impossibilidade de simplesmente fazê-lo ou de nela manter-se por muito tempo, num jogo de revelação e ocultamento, como formula a primeira das epígrafes de Tezza, é certo que a veiculação midiática do 
livro não deixou de se valer da ideia de uma confissão sem concessões do autor como estratégia mercadológica para a sua circulação. Na orelha da sua primeira edição, lemos que, "Num livro corajoso, Cristovão Tezza expõe as dificuldades [...] de criar um filho com síndrome de Down. O autor aproveita as questões que apareceram pelo caminho nestes 26 anos de Felipe para reordenar sua própria vida" (TEZZA, 2007). O que temos aqui, menos que uma caracterização da singularidade autoficcional do romance, é tão somente a promessa de revelação da vida pessoal do autor e da superação de seus problemas por meio de uma escrita "reordenadora da vida”. Apesar da sofisticação de asserções teóricas segundo as quais a autoficção joga com a suspensão dos limites entre referencialidade e exercício criativo, na curiosidade do público e nas estratégias de mercado o que muitas vezes prevalece é o desejo biográfico e o acesso voyeurista ao privado, acrescidos da socialização do poder curativo da escrita de si. Da mesma forma, em que pesem as estratégias de ficcionalização da vida inscritas e estetizadas como romance, o que anima diversas das perguntas dirigidas ao autor em entrevistas por ele concedidas é, não raro, certa intrusão biográfico-autoral:

\begin{abstract}
[...] eu estava mexendo em um vespeiro ao escrever sobre isso [um pai com uma criança especial]. Ao mesmo tempo, é um livro muito pessoal, em que eu exponho, ou mesmo escancaro minha própria vida e meus sentimentos aos leitores; [...] [Pergunta] Por conta de toda produção acadêmica que existe sobre a obra e pelo fato de o personagem do livro também se chamar Felipe, como seu filho Felipe se sente? [Resposta] Ele não tem a percepção cognitiva, psicológica para entender a complexidade que está no livro. O que ele entende é que o livro é sobre ele e, para ele, isso é maravilhoso por si só (TEZZA, 2018, p. 237).
\end{abstract}

Apesar de por vezes problematizado, ${ }^{5}$ o mantra da coragem confessional caiu no gosto da própria crítica, que, em vez de se concentrar na materialidade e no trabalho específico da escrita (auto)ficcional, aposta na complexidade do tema e sua relação delicada com a biografia do autor como vestígios de uma qualidade apriorística e, portanto, inevitável da obra. "Coragem", "sensibilidade", "sinceridade", "crueldade", "verdade", "vergonha”, entre outros, compõem um quadro crítico e conceitual que se situa, a bem da verdade, muito próximo da nomenclatura romântico-confessional ou da leitura estrita de biografias. Segue disso a inevitável pergunta: até que ponto os procedimentos anunciados pelo rico debate teórico acerca da autoficção de fato migram para uma leitura pública do

${ }^{5}$ Cf. Damasceno (2019). 
gênero como um conjunto de artifícios criativos ou estratégias ficcionais (DAMASCENO, 2019)? Ou permaneceríamos aqui fundamentalmente no domínio do confessional, gerando protocolos de leitura que, no lugar da concretude do artefato artístico e de seu funcionamento, inserem o espaço biográfico como catalisador da experiência literária e de uma escrita "reparadora", capaz de despertar a curiosidade do leitor?

Para além da ficcionalização do eu e do jogo de suspensão referencial, o chamado boom da autoficção parece nos lançar também ao coração dessas questões, a esse instante em que a literatura e a crítica literária flertam de perto com uma linguagem terapêutica, curativa, cicatrizante. Lado a lado com a "função" artístico-literária ou a condição de artefato estético dos objetos, impõe-se igualmente a atestação ou verificação de um projeto ético-reparador: exercício híbrido de cancelamento dos limites entre fato e ficção, a autoficção "ensina” a lidar com a perda, permite a cura, expurga o trauma, preenche lacunas, gera empatia, confere visibilidade, desfaz injustiças etc. Se é verdade que a constante reiteração da dificuldade de estabelecer fronteiras claras para os papéis de autor/ narrador/personagem ou para a relação entre memória/verdade/criação não assegura um encontro crítico e produtivo com as obras - constituindo um lugar comum, digamos -, o peso final da análise em muitos casos é decidido pela ou recai sobre a potência ético-política de seus temas, ou melhor, sobre a possibilidade de, mais uma vez, revisitar o passado, abrir espaço para memórias alternativas ou, de forma mais direta, possibilitar a reconciliação com o mundo.

Como um último vetor decisivo desse fenômeno, vale a pena apontar o atual alinhamento entre a literatura autoficcional e a exposição ficcionalizada de si, com pretensões literárias, que ocorre nas mídias sociais. Em canais como twitter, facebook, instagram, entre outros, os impulsos criativos alinham-se à imediaticidade de uma recepção que "curte", "descurte", "segue" ou "deixa de seguir" segundo o critério do estímulo. Logicamente, essa dinâmica tende a colocar em primeiro plano o propósito de atender ao leitor, o que acaba por conduzir, uma vez mais, ao terapêutico ou, neste caso particular, ao "consolo" e à autoajuda. As linhas iniciais de uma recente reportagem da Folha de São Paulo sobre os novos "Escritores do instagram" resumem a questão da seguinte maneira: "Assim como um celular já não é feito só para ligações, os contos e os poemas não são mais escritos apenas para serem lidos. É preciso curtir, comentar, marcar os amigos, seguir o autor e assistir às suas recomendações” 
(MOLINERO, 2019, [s.p.]). O mesmo é verdade do ponto de vista de quem produz: "os escritores, é claro, [...] deram adeus ao mundo no qual a única preocupação criativa é a folha em branco - agora é necessário analisar métricas on-line, calcular alcances e estudar como gerar engajamento e aumentar os seguidores" ([s.p.]). Diferentemente da produtividade do discurso crítico sobre a autoficção e seus artefatos mais rigorosos, salta aos olhos aqui o pragmatismo confesso, isto é, a continuidade imediata entre escrita, profissão, utilidade e a esfera econômica: "Sucesso nas redes sociais, nas quais mobilizam centenas de milhares de fãs com pequenos textos quase sempre sentimentais e motivacionais, os autores de Instagram fazem cada vez mais os olhos das editoras brilharem - e seus bolsos salivarem" ([s.p.]).

Dados o jogo do efeito imediato e a dinâmica da concisão, característicos das mídias sociais, a literatura aqui caminha rumo à compressão e aos gêneros cada vez mais curtos. A chamada "tuiteratura" ou "twitteratura", por motivos óbvios, restringe os textos literários ao limite de 280 caracteres, o que não significa necessariamente o "tratamento direto" do objeto ou uma "estética da compressão", conforme os termos de um imagismo clássico que prega economia e precisão. Associada à explosão recente dos gêneros ou formas breves - microcontos, nanocontos, microrrelatos, microficções, micropoemas, minicontos, aforismos, haicais -, mas sem necessariamente manter o rigor de muitos destes, a "tuiteratura", entre suas particularidades formais, emerge com data de nascimento, horário da postagem, número de curtidas, retweets etc. Dessa forma, fincada no tempo e com "prazo de validade" - a menos que migre para o formato livro -, trata-se de uma "literatura dos fatos cotidianos", que atende às necessidades e intervenções do leitor para então migrar para o desaparecimento. Nas descrições habituais do fenômeno, aparece constantemente o propósito de "ensinar" o leitor, "aprender" com o leitor e, mais importante, estimular uma rede de seguidores valendo-se, se necessário, de estratégias de mercado: "como veículo de marketing, a tuiteratura pode erguer os autores estabelecidos a novas alturas [...]. Efêmeros ou não, os tweets 'ensinam', informando tanto autores novos quanto antigos sobre como alcançar e atrair leitores” (RUDIN, 2011, [s.p.]).

Mas a construção ficcionalizada do "eu" autoral e seus jogos subsequentes de presença/ausência, verdade/construção, exposição/ ocultamento é apenas um dos diferentes retratos assumidos pela leitura e produção ético-reparadoras hoje. Vale a pena lembrar o alcance teórico 
dessa tendência conforme cristalizado pela chamada "virada ética" nos estudos literários. Ora, se é certo que o vínculo entre ética e literatura é histórico e também constitutivo do campo, como o célebre livro $\mathrm{X}$ da República de Platão não deixa de nos lembrar, a "virada ética" muitas vezes se confunde atualmente com o todo da própria atividade da crítica literária, principalmente por meio do mecanismo mediador dos studies: "estudos animais", “estudos queer", “estudos pós-humanos", "estudos visuais", "estudos da adaptação" etc. A premissa fundamental, que talvez possa unir os diversos desdobramentos e particularidades dos diferentes studies, é a de que a literatura constitui um lugar privilegiado para as discussões em torno de decisões éticas que atravessam as diferentes formas de hierarquias e exclusões sobre as quais a nossa sociedade se estrutura (CULLER, 2016). Em volume sobre o tema, os organizadores Todd Davis e Kenneth Womack apresentam a "virada ética" nos seguintes termos:

\begin{abstract}
Parte de ser humano envolve a luta diária com os significados e as consequências de nossas ações, uma luta mais frequentemente entendida a partir das estruturas narrativas, quando dizemos aos outros e a nós mesmos o que ocorreu ou o que tememos que ocorra no futuro. Como criaturas dirigidas pela história, nos encontramos imersos em narrativas em quase todos os aspectos de nossas vidas. [...] No fim das contas, se existe alguma característica definidora da virada ética que marca os estudos literários contemporâneos, esta reside no fato de que poucos críticos desejam retornar a uma forma de leitura dogmática, prescritiva ou doutrinária (DAVIS; WOMACK, 2001, pp. ix-x, tradução nossa).
\end{abstract}

O breve prefácio para o livro, contudo, admite que a "virada ética" ali mapeada constitui menos um conjunto consistente de posições teórico-críticas diante do literário do que um desejo de recusar "formas de leitura dogmáticas, prescritivas ou doutrinárias” por meio do encontro ou confronto com questões controversas e com o poder das narrativas de "mudar as nossas vidas" (BOOTH, 2001, p. 18). Em outras palavras, a abertura oferecida pela "virada ética" ocorre sobretudo no campo temático, e é aí que o dispositivo dos studies insere-se num esquema capaz de "atualizar-se" ad nauseam, sob o risco, é claro, de também colocar-se a serviço de um semelhante "efeito de moda": os temas surgem, informam os artefatos a partir de seus teóricos, fundam uma área (" $\mathrm{x}$ " studies) $\mathrm{e}$ caem em desuso depois de certo tempo. Do ponto de vista da crítica e do encontro com as obras, de um lado, em seu procedimento analítico mais efetivo, os "estudos" são também afetados pelos objetos com que se deparam, num exercício imprevisível e de contágio mútuo, que não silencia a imanência ou singularidade do literário em seu anseio teórico 
de celebrar as suas premissas; de outro lado, no pior dos cenários, ocorre aquilo que Fabio Durão (2017a, p. 31) observa no ensaio intitulado "Burrice acadêmico-literária brasileira": "Artigos e mais artigos são escritos com o objetivo de mobilizar certos termos em voga"; "teorias são aplicadas aos mais diversos (e díspares) objetos”. Neste último caso, as leituras por vezes convertem-se em exercícios mecânicos e previsíveis, sem muito dialogar com o conhecimento eventualmente desconcertante da especificidade que cada artefato traz consigo.

De todo modo, o que chama a atenção na "virada ética" é o frequente anúncio e celebração do poder "curativo", "benéfico", "político" e "esclarecedor" da literatura, tese cujas circularidade e reiteração - por exemplo, no volume supracitado (DAVIS; WOMACK, 2001) - por si só denotam a angústia diante de um possível "vazio" ou dispêndio da leitura literária, ou então da sua própria inutilidade, que parece pairar sobre o argumento ético-reparador como ameaça constante. É como sea promessa de aprender com a literatura se antecipasse e ocupasse um primeiro plano em relação à prática da crítica e aos textos que de fato podem ou não - só é possível afirmá-lo depois do teste da leitura - "ensinar" algo por meio de suas operações particulares e de sua constituição específica. Aproximar-se dos animais e dos humanos, sensibilizar quanto à alteridade da natureza, reviver os traumas e rememorar o passado sob outra ótica, reconhecer e aceitar as diferenças, questionar oposições binárias, reconstruir-se a si mesmo ficcionalmente, em suma, reparar o mundo: a maquinaria ética reajusta e amplia o seu alcance na exata medida em que se confirmam e se modificam os conflitos humanos, de modo a justificar pragmática e politicamente a relevância da literatura e dos estudos literários. É justamente como espaço terapêutico e repositório de alteridades que Todorov (2009, p. 76) reitera o lugar privilegiado de uma atividade criativa agora "em perigo":

A literatura pode muito. Ela pode nos estender a mão quando estamos profundamente deprimidos, nos tornar ainda mais próximos dos outros seres humanos que nos cercam, nos fazer compreender melhor o mundo e nos ajudar a viver. Não que ela seja, antes de tudo, uma técnica de cuidados para com a alma; porém, revelação do mundo, ela pode também, em seu percurso, nos transformar a cada um de nós a partir de dentro.

Ali onde essas posições ético-reparadoras mais ganham força, embora esvaziadas da complexidade do debate teórico, é, de fato, na Educação Básica e nos documentos oficiais que dispõem sobre o lugar do ensino da 
literatura nos currículos escolares. Na versão final da Base Nacional Comum Curricular Brasileira (BNCC), datada de 2018, melhoria individual, expressão de si, reconhecimento das alteridades e "protagonismo e autoria na vida pessoal e coletiva" (BRASIL, 2018, p. 9) misturam-se num todo confuso que, no fim das contas, tão somente dissolve qualquer solidez vinculada ao literário em nome do mesmo discurso de flexibilidade formativa que domina as demais linhas do documento. A fim de preencher o espaço vazio deixado pela crise do discurso de nação e da história da literatura que lhe é correspondente, pelo elitismo, parcialidade e arrogância do cânone ocidental, pela dificuldade de oferecer uma caracterização estável para a chamada "literariedade", pelo desgaste da Bildung e dos demais conceitos associados a um humanismo agora descartado como eurocêntrico operadores que até recentemente justificavam a presença do literário nas escolas -, a BNCC vale-se de um pressuposto ético não de todo dessemelhante daquele antes visto. A imagem do literário, entretanto, é esgarçada a ponto de nela caber qualquer forma narrativa e gênero textual, acompanhados agora de uma improvável pirotecnia de tecnologias e mídias sociais. De resto, vale a pena destacar ainda - quem sabe pela primeira vez em documento oficial -, a aparição da escrita criativa como habilidade a ser desenvolvida para a promoção do autoconhecimento:

\footnotetext{
Estáem jogo, também, nesta etapa [Ensino Médio], um trabalho mais sistemático com a escrita literária, o fazer poético, cujo trabalho é lento e demanda seleções e experimentações de conteúdo e de recursos linguísticos variados, tendo em vista um interlocutor. Com isso, tais escolhas podem funcionar como processo de autoconhecimento, ao mobilizar ideias, sentimentos e emoções (BRASIL, 2018, pp. 523-524).

[Habilidade] Produzir apresentações e comentários apreciativos e críticos sobre livros, filmes, discos, canções, espetáculos de teatro e dança, exposições etc. (resenhas, vlogs e podcasts literários e artísticos, playlists comentadas, fanzines, $e$-zines etc.).

$[\ldots]$

[Habilidade] Criar obras autorais, em diferentes gêneros e mídias - mediante seleção e apropriação de recursos textuais e expressivos do repertório artístico -, e/ou produções derivadas (paródias, estilizações, fanfics, fanclipes etc.), como forma de dialogar crítica e/ou subjetivamente com o texto literário (BRASIL, 2018, p. 526).
}

As profundas novidades tecnológicas e midiáticas que acompanham e justificam o literário na BNCC apenas revelam um elemento contrário desconfortável ou indesejado, isto é, a insuficiência ou mesmo descartabilidade da área, se tomada como um fim em si mesma e se 
dissociada de um esquema de meios e fins que lhe confira um sentido ético-formativo regulador. Muito embora um tal sentido seja, no fim das contas, até muito bem-vindo, aqui ele se constitui na contramão ou "nas costas" dos objetos e formas historicamente associados à literatura, dissolvendo-a ou evaporando-a em meio a uma profusão ininterrupta de gêneros e tecnologias que, a rigor, têm eles próprios uma vida bastante instável. O que vemos na nova BNCC é um conceito ampliado de literatura que flerta perigosamente com a sua própria dissolução e descarte, o que, neste caso, tem uma consequência imediata e evidente: os estudos literários convertem-se em um misto pré-teórico de creative writing, "estudos de mídia" e "gêneros do discurso", um híbrido destituído de qualquer vestígio do seu passado e de sua memória, mas que insiste em arrastar consigo um nome que já não lhe satisfaz mais.

\section{APONTAMENTOS FINAIS}

O desejo de "reparar o mundo" - para recordar aqui uma última vez o título do livro de Alexandre Gefen (2017) - confere à literatura um propósito objetivo e nobre que, a rigor, não deixa de contrastar tanto com o diagnóstico recorrente do seu eventual fim quanto com a tradição da poética do esgotamento, característica de alguns dos instantes decisivos da trajetória crítico-literária ao longo do século XX. Seja como for, num momento claramente definido pela profunda disputa ou concorrência entre diferentes textualidades, mídias e gêneros no campo de visibilidade da cultura, ou mesmo rivalizando com o poder de sedução e estímulo, entre outros, de videogames, quadrinhos, adaptações intermidiáticas, isso para não citar twitter, facebook, instagram, youtube e seus congêneres, a literatura vê-se obrigada a, de um lado, alargar o seu conceito de modo a incluir tudo isso como expressões "protoliterárias" ou reconfigurações correntes suas, e, de outro, adentrar também ela o espaço positivo do pragmatismo contemporâneo, isso sob a sombra das ameaças e do risco iminente de desaparecer como forma dos espaços institucionais. Nesse sentido, compreender o trabalho da literatura como aquele de remediar, restituir, dar visibilidade, fazer justiça, lembrar etc., é um movimento que confere à área, é claro, ares de uma profunda revitalização, assegurando-lhe certa proeminência imprevista, pelo menos discursiva.

O que vale a pena considerar - e esse foi o propósito principal deste ensaio - é que o princípio ético-reparador do uso corresponde em grande parte à neutralização de um outro "uso" possível para o literário, isto é, 
para a sua política da negação e da intransitividade, que, curiosamente, teria um papel não menos importante a cumprir no presente momento. Em outras palavras, o entendimento de que a literatura e o seu ensino são intransitivos (DURÃO, 2017b), de que não há nada que a literatura instrumentalize diretamente como efeito de suas operações ou como conduta (des)construtiva sua, está muito longe de significar que ela não tem relevância alguma ou que não tenha dimensão ético-formativa alguma. Ora, se são verdadeiros os diagnósticos, repetidos à exaustão, de que a contemporaneidade é marcada pelo signo da competição, do espetáculo de si, da cultura do eu, da busca incessante por estímulos, da política do efeito, da transparência, das notícias falaciosas, do cansaço etc., a "improdutividade" da literatura poderia vincular-se à introspecção, ao silêncio, à lentidão e a outras formas negativas cuja "inutilidade" ganha hoje contornos dramáticos e radicais. No entanto, seguindo o diagnóstico de Debord (1997, pp. 16-17) acerca da linguagem democrática do espetáculo - "o que aparece é bom, o que é bom aparece" -, resta a seguinte pergunta: Em meio a tantos ruídos, como apontar a relevância e sustentar o lugar fundamental daquilo que caminha silenciosamente, sem ser visto, para o desaparecimento?

\section{REFERÊNCIAS}

ADORNO, Theodor W. Prismas: crítica cultural e sociedade. Trad. Augustin Wernet e Jorge Mattos Brito de Almeida. São Paulo: Ática, 1998.

AZEVEDO, Luciane Almeida de. Autoficção e literatura contemporânea. Revista Brasileira de Literatura Comparada, n. 12, 2008, pp. 31-49.

BARTHES, Roland. O rumor da língua. Trad. Mário Laranjeira. São Paulo: Martins Fontes, 2004 .

BATAILlE, Georges. A parte maldita; A noção de dispêndio. Belo Horizonte: Editora Autêntica, 2013.

BECKETT, Samuel. O inominável. Trad. Ana Helena Souza. São Paulo: Globo, 2009.

BERARDINELLI, Alfonso. Não incentivem o romance e outros ensaios. Trad. Doris Nátia Cavallari, Francisco Degani e Patrícia de Cia. São Paulo: Nova Alexandria, 2007.

BLANCHOT, Maurice. A parte do fogo. Trad. Ana Maria Scherer. Rio de Janeiro: Rocco, 1997. 
BOOTH, Wayne C. Why Ethical Criticism Can Never Be Simple. In: DAVIS, Todd F.; WOMACK, Kenneth (Eds.). Mapping The Ethical Turn: A Reader in Ethics, Culture, and Literary Theory. Charlottesville/London: University Press of Virginia, 2001, pp. 16-29.

BOULTER, Jonathan. Melancholy and the Archive: Trauma, Memory, and History in the Contemporary Novel. New York: Continuum, 2011.

BRASIL. Ministério da Educação. Base Nacional Comum Curricular (BNCC). Ensino Médio. Brasília, 2018.

CECHINEL, André. Semiformação Literária: a instrumentalização da literatura na nova BNCC. Educ. Real., Porto Alegre, v. 44, n. 4, 2019, pp. 1-13. Disponível em: <http:// www.scielo.br/scielo.php?script=sci_arttext\&pid=S2175-623620190004006o9\&lng= pt\&nrm=iso >. Acesso em: 6 jan. 2020.

COMPAGNON, Antoine. Literatura para quê? Trad. Laura Taddei. Brandini. Belo Horizonte: Editora UFMG, 2009.

CRARY, Jonathan. 24/7: capitalismo tardio e os fins do sono. São Paulo: Cosac Naify, 2014.

CULLER, Jonathan. Teoria literária hoje. In: CECHINEL, Andre (Org.). O lugar da teoria literária. Florianópolis/Criciúma: EdUFSC/Ediunesc, 2016, pp. 395-417.

DAMASCENO, Carolina Duarte. Intencionalidade autoral e escritas de si: uma proposta de reflexão. In: CUNHA, Betina Ribeiro Rodrigues da; LIMA, Rogério da Silva (Orgs.). Circulação, tramas e sentidos na literatura. Rio de Janeiro: Bonecker, 2019, pp. 79-9o.

DAVIS, Todd F.; WOMACK, Kenneth (Eds.). Mapping The Ethical Turn: A Reader in Ethics, Culture, and Literary Theory. Charlottesville/London: University Press of Virginia, 2001.

DEBORD, Guy. A sociedade do espetáculo. Trad. Estela dos Santos Abreu. Rio de Janeiro: Contraponto, 1997.

DIX, Hywel. Introduction: Autofiction in English: The Story so Far. In: DIX, Hywel (Ed.). Autofiction in English. London: Palgrave, 2018, pp. 1-23.

DURÃO, Fabio. Burrice acadêmico-literária brasileira. Revista da Anpoll, Florianópolis, n. 43, jul./dez. 2017a, pp. 19-33.

DURÃO, Fabio. Da intransitividade do ensino de literatura. In: CECHINEL, André; SALES, Cristiano de (Orgs.). O que significa "ensinar" literatura? Florianópolis/Criciúma: Edufsc/Ediunesc, 2017b, pp. 15-29.

DURÃO, Fabio. Do texto à obra e outros ensaios. Curitiba: Appris, 2019a. 
DURÃO, Fabio. Sobre a memória na sociedade da imagem. In: CECHINEL, André; MUELLER, Rafael Rodrigo (Orgs.). Formação humana na sociedade do espetáculo. Chapecó/Criciúma: Argos/Ediunesc, 2019b, pp. 257-28o.

DURÃO, Fabio A.; TINTI, Tauan. Discutindo a máquina acadêmica. In: DURÃO, Fabio A. Metodologia de pesquisa em literatura. São Paulo: Parábola, 2020, pp. 81-100.

EHRENBERG, Alain. La fatigue d'être soi. Dépression et société. Paris: Odile Jacob, 1998.

GEFEN, Alexandre. Réparer le monde. La littérature française face au XXIe siècle. Paris: Éditions Corti, 2017.

JAPPE, Anselm. A sociedade autofágica: capitalismo, desmesura e autodestruição. Trad. Júlio Henriques. Lisboa: Antígona, 2019.

KAFKA, Franz. O castelo. Trad. Modesto Carone. São Paulo: Companhia das Letras, 2000.

LISPECTOR, Clarice. Água viva. Rio de Janeiro: Rocco, 1998.

MANN, Thomas. A montanha mágica. Trad. Herbert Caro. Rio de Janeiro: Nova Fronteira, 2006.

MOLINERO. Escritores do Instagram seduzem editoras com textos para consolar e viralizar. Folha de São Paulo, 8 de nov., 2019. Disponível em: <https://www1.folha. uol.com.br/ilustrada/2019/11/escritores-do-instagram-seduzem-editoras-comtextos-para-consolar-e-viralizar.shtml>. Acesso em: 21 mar. 2020.

PERRONE-MOISÉS, Leyla. Mutações da literatura no século XXI. São Paulo: Companhia das Letras, 2016.

RABATÉ, Dominique. Vers une littérature de l'épuisement. 2. ed. Paris: Éditions Corti, 2004.

RABATÉ, Dominique. La passion de l'impossible: une histoire du récit au XXe siècle. Paris: Éditions Corti, 2018.

RUDIN, Michael. From Hemingway to Twitterature: The Short and Shorter of It. JEP - Journal of Electronic Publishing, v. 14, n. 2, 2011. Disponível em: <http://dx.doi. org/10.3998/3336451.0014.213>. Acesso em: 21 mar. 2020.

RULFO, Juan. Pedro Páramo e O chão em chamas. Trad. Eric Nepomuceno. 5. ed. Rio de Janeiro: Record, 2008.

SISCAR, Marcos. Poesia e crise: ensaios sobre a "crise da poesia" como topos da modernidade. Campinas: Editora da Unicamp, 2010.

SISCAR, Marcos. De volta ao fim: o "fim das vanguardas" como questão da poesia contemporânea. Rio de Janeiro: 7 Letras, 2016. 
STEINER, George. O silêncio dos livros. Lisboa: Gradiva, 2007.

TEZZA, Cristóvão. O filho eterno. 2. ed. Rio de Janeiro: Record, 2007.

TEZZA, Cristóvão. [Entrevista a Lucas Breda Magalhães et al.]. Claraboia, Jacarezinho/PR, v. 9, jan./jun., 2018, pp. 234-243.

TODOROV, Tzvetan. A literatura em perigo. Trad. Caio Meira. 2. ed. Rio de Janeiro: Difel, 2009.

WALSER, Robert. Absolutamente nada e outras histórias. Trad. Sergio Tellaroli. São Paulo: Editora 34, 2014.

Recebido: 21/3/2020

Aceito: 15/7/2020

Publicado: 21/6/2021 